\title{
A Dynamic Model to Evaluate the Balance between Demand and Supply of Water Resources
}

\author{
Mingkai Liu \\ School of Power Engineering, North China Electric Power University, Baoding 071000, China \\ 295338900@qq.com
}

Keywords: Water resources,Agriculture,Industry,Domestic

\begin{abstract}
Water scarcity has attracted plenty of attention from all over the world for recent decades. Comprehensive models need to be established to evaluate and solve this problem.This paper first build a dynamic model to evaluate the balance between demand and supply of water resources. The WSI indicator is used to express relationship between water demand and supply. The total demand is divided into three aspects. We define different calculation formulas which are related to industrial pollution,planting area and population. While the total supply is the addition of groundwater, the surface water, the trans-regional water drainage and the water in the reservoir. Economical scarcity is taken into our model consideration through the index NDI, which is the ratio of the water deficit and rainfall.Water resources carrying capacity evaluation model system is the comprehensive three-level hierarchy structure analysis, to evaluate water situation of the South Carolina.
\end{abstract}

\section{Introduction}

With the increasing water scarcity and the associated deterioration of the quantity and quality of water sources in many parts of the world, water shortage has become a hot issue of the era. What is even more frightening is that the world population will double by 2025, 40 countries and regions will face freshwater scarcity[1]. Water use has been growing at twice the rate of population over the last century. The causes of drought in the United States history can be roughly divided into the following categories: population increase, continuous drought and water pollution. While, these problems were solved by several measures such as water resources protection, solving of the Delta problems of America, constructing reservoir and dam and the recycling of water[2,3].

Considering the dynamic nature of the factors that affect both supply and demand,we develop WSI index and NDI index to measure the ability of a region to provide clean water to meet the needs of its population.Then we pick South Carolina,a moderately overloaded place,using the WSI index to make out why and how water is scarce in that region through the social and environmental drivers by addressing physical and economic scarcity.

\section{Clean water providing dynamic model}

According to the risk assessment of water in the United States, water demand can be divided into the following several aspects: domestic water, industrial water, water used in agricultural and water used in other aspects, including the business, mining, plant breeding and public provision.

At the same time, water supply is restricted by two aspects: physical scarcity and economic scarcity. The physical part include water area, rainfall capacity and geographical position and the economic part include the population, GDP, technical level, infrastructure construction and the power generation.

The task of this part is establishing a dynamic supply and demand model to evaluate the ability of providing clean water of a region. Due to a region's ability to provide clean water influenced by multiple factors. So some parameters need being introduced in front of the model's establishing.

$$
N D I=\frac{S I I_{j}}{A P_{j}}
$$




$$
\begin{aligned}
& S I I_{j}=\max _{t}\left(\text { deficit }_{j, t} ; t=1: n * 365\right) \\
& \text { Deficit }_{j, t}=\max \left(\text { deficit }_{j, t-1}+D_{j, t}-S_{j, t}\right)
\end{aligned}
$$

Where the $A P$ stands for average annual rainfall.

Where the SII stands for the maximum deficit.

Where the NDI stands for the regional water storage ability.

For location "j”"on day “t”of year “y”.

\section{Model establishing}

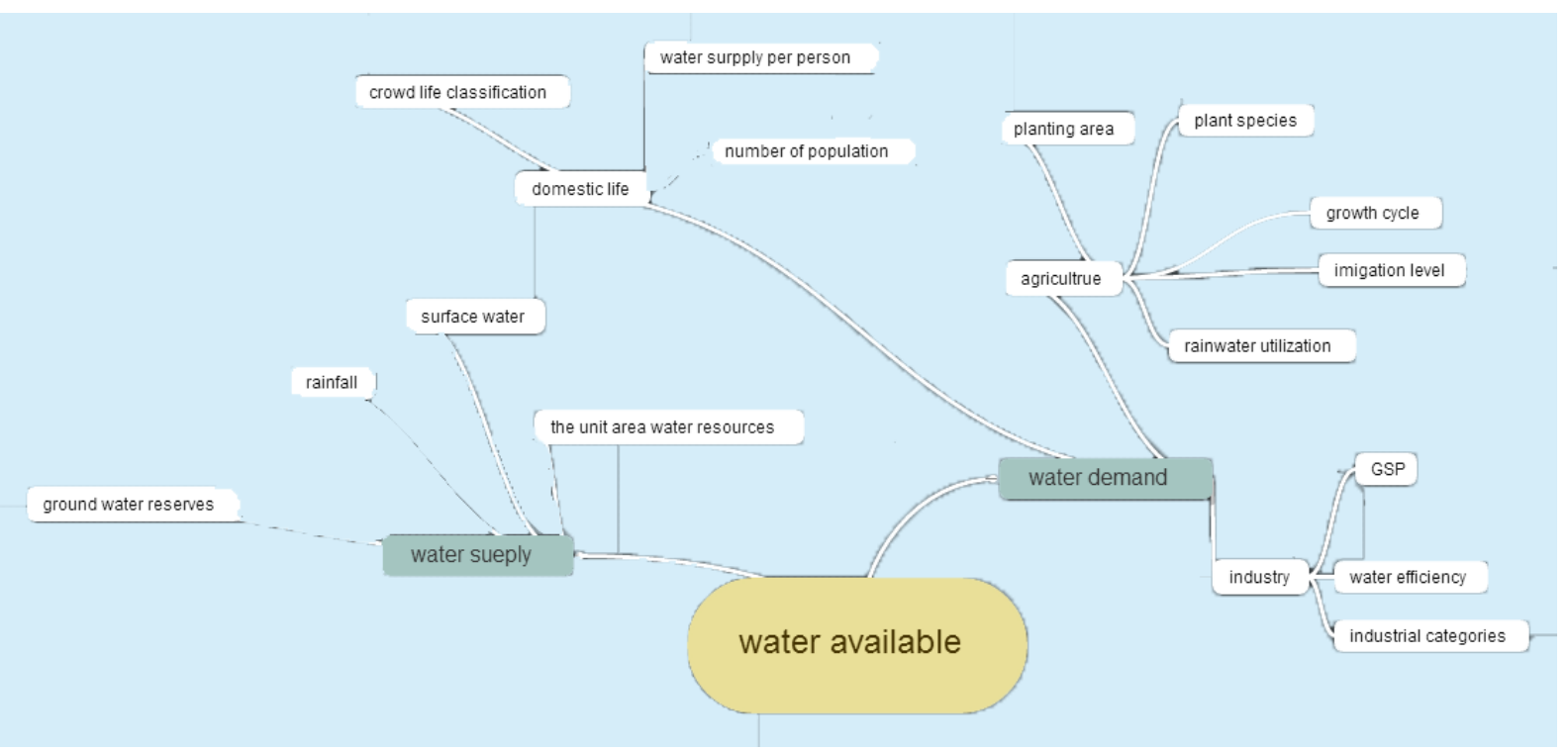

Fig 1. the diagram of the factors under the consideration

\subsection{Water Demand of Agriculture}

In the aspect of agriculture, the dynamic supply and demand model is established to express a region's ability to provide clean water. As we all know, all the crops can be divided into eight species. Each grain has their different water features, the potential crop transportation has an undeniable influence on the crop water requirement. Absolutely, the most important indicator is the planting area of eight types of crops[3]. Considering the factors above, we list the demand equation as follow.

At the same time, The number of water also is influenced by many factors. The amount of rainfall affects a region's water supply capacity. If a region often rains, it is undoubtedly rich in water resources. On the contrary, if a region is in a continent drought, the water resources in this area is generally poor. Alike the conclusions before, the net cropped area is still a very crucial aspect of balancing the water richness of an area. Considering the factors above, we list the supply equation as follow.

$$
A_{t}^{j}=\sum_{m=1}^{m=8} \frac{k_{c m}}{\beta_{m}} E T_{0 t}^{j} C A_{t}^{j, m}
$$

Where the $k_{c m}$ stands for the crop coefficient.

Where the $A$ stands for the total demand of water.

Where the $S$ stands for the total supply of water.

Where the $C A_{t}^{j, m}$ stands for the planting area of eight types of crops.

Where the $E T_{0 t}^{j}$ stands for the growing cycle time of crops.

Where the $\beta_{m}$ stands for the irrigation efficiency of crops. 


\subsection{Water Demand of Industry}

In the aspect of industry, the dynamic supply and demand model is established to express a region's ability to provide clean water. Basic principle is consistent with the above analysis of agriculture. The industrial production can be divided into three types: The light industry, the heavy industry and the automation industry. It is not same that the water consumption of different industries in America. Industrial water consumption is under the influence of various aspects. As same as the above analysis, industrial production cycle has influence on the water consumption. So we take this aspect into our consideration to build the model. We also consider the influence of industrial production output, which is the objective reflection of economic level. We consider the economic shortages by balancing the industrial output. The demand and supply equation are listed as follow:

$$
I_{t}^{j}=\sum_{m=1}^{3} \frac{L}{\lambda_{m}} E T_{0 t}^{j} W_{t}^{j, m}
$$

Where the $\boldsymbol{I}_{t}^{j} \quad$ stands for the water demand of industry.

Where the $W_{t}^{j, m} \quad$ stands for the total output of industry.

Where the $L$ stands for the type coefficient of different works.

Where the $\lambda_{m}$ stands for the industrial production efficiency.

\subsection{Water Demand of Domestic Life}

In the aspect of domestic life, the dynamic supply and demand model is established to express a region's ability to provide clean water. The basic principle is like the first two questions too. The differences lie in the the division of the domestic water. The classification of the domestic water is the water consumption in city community, enterprise, rural regions and the public places. One problem which must be paid special attention to is the increasing number of the population. The increasing of population leads to the increase of the total potable water, and makes the degree of water pollution rise up. In the same way, the domestic water supply is influenced by the population as well. So we add the demographic factor into not only the supply equation but also the demand equation.

$$
D_{t}^{j}=\sum_{m=1}^{4} \frac{T_{m}}{\gamma_{m}} R_{t}^{j, m}
$$

Where the $D_{t}^{j} \quad$ stands for the water demand of domestic life.

Where the $S_{D t}^{j} \quad$ stands for the water supply of domestic life.

Where the $R_{t}^{j, m}$ stands for the demographic factors in domestic life.

Where the $T_{m} \quad$ stands for the water efficiency coefficient.

Where the $\gamma_{m}$ stands for the type coefficient of different life.

We use the indicator WSI to represent the whole dynamic model of supply and demand. This index comprehensively consider the water demand and supply of agriculture, industry and domestic life. We express the total amount of water supply as follow:

$$
\begin{gathered}
S=\partial_{1} W_{1}+\beta_{2} W_{2}+\gamma_{3} W_{3}+\eta_{4} W_{4} \\
W S I=\frac{(D I A)^{\partial}}{S} \\
\partial=N D I \\
D I A=D+I+A
\end{gathered}
$$

Where the $S$ stands for the total amount of water supply of three aspects.

Where the $\partial_{1}, \beta_{2}, \gamma_{3}, \eta_{4}$ stands for the balance index of the dynamic model.

Where the $W_{1}, W_{2}, W_{3}, W_{4}$ are respectively stand for the water coefficient for different water resources. Where the WSI are respectively stand for the groundwater, the surface water, the trans-regional water drainage and the the water in the reservoir. 
We use the dynamic model to evaluate a region's ability to provide clean water. If the value is large, this result can prove that the ability of providing clean water in this area is non-ideal. On the contrary, if the value is small, this result can prove that the ability of providing clean water in this area is ideal. Correspondingly, the value of WSI which is between the maximum and the minimum value of the WSI, representing different levels of ability to provide clean water.

\section{Water Situation of the South Carolina}

The results are provided as different weight vectors of different factors. The average WSI is 11.25 in 2015, which confirms that the South Carolina is moderately overloaded. According to the weight vectors, economical factors account more than physical factors. This scarcity is mainly leaded by economical factors related to population and update of production equipment.We obtain the WSI of the years from 2001 to 2030 in South Carolina based on the data searched by us[4,5].

Table 1 the WSI of the years from 2001 to 2015 in SC

\begin{tabular}{llllllll}
\hline 01 & 02 & 03 & 04 & 05 & 06 & 07 & 08 \\
\hline 10.0 & 10.2 & 10.5 & 10.3 & 10.6 & 10.8 & 10.6 & 10.8 \\
09 & 10 & 11 & 12 & 13 & 14 & 15 & \\
11.1 & 10.7 & 10.9 & 11.3 & 10.8 & 11.0 & 11.6 & \\
\hline
\end{tabular}

\section{Conclusion}

In this study, the molecular is the total water demand which is defined as the addition of the water demand of agriculture, industry and domestic life. The denominator is the total water supply which is defined as the results of the addition of the four types of water supply of the groundwater, the surface water, the trans-regional water drainage and the water in the reservoir.

We use the dynamic model to evaluate a region's ability to provide clean water. If the value is large, this result can prove that the ability of providing clean water in this area is non-ideal. On the contrary, if the value is small, this result can prove that the ability of providing clean water in this area is ideal. Correspondingly, the value of WSI which is between the maximum and the minimum value of the WSI, representing different levels of ability to provide clean water.

\section{Acknowledgments}

This work was financially supported by "A study based on the heat pipe condenser type grain drying device "(201510079048), which belongs to the innovation and Entrepreneurship Program for College Students in North China electric power university.

\section{References}

[1] Daniel Shi, Naresh Devineni ,Columbia Water Center White Paper America's Water Risk: Water Stress and Climate Variability,2014.

[2] BURAS N Scientific allocation of water resources:water resources development and utilization-arational approach 1972.

[3] UN FAO.2013.AQUASTAT database.Rome,Italy:Food and Agriculture Organization of the United Nations. 
[4] Frenken, K., ed. Estimates from UN FAO. 2005. Irrigation in the Middle East Region in Figure s. AQUASTAT Survey-2008.

[5] United States Geological Survey revised: conterminous US (2071); Alaska (980); Hawaii (18). M. Eurostat, U. Wieland. 2003. Water Resources in the EU and in the Candidate Countries. Statistics in Focus, Environment and Energy, European Communities. 